\title{
DE MAR A MAR: CORRESPONDENCIA ENTRE ANA MARÍA MOIX Y ROSA CHACEL ${ }^{1}$
}

\author{
Andrea Santamaría Villarroya ${ }^{2}$
}

\begin{abstract}
Título en Español: De mar a mar: Correspondencia entre Ana María Moix y Rosa Chacel
Resumen: De mar a mar es el título del epistolario que recoge la correspondencia entre las escritoras Ana María Moix, que cuenta con tan solo dieciocho años y Rosa Chacel, ya de sesenta y siete y exiliada en Río de Janeiro. Estas mujeres entablan una sincera amistad que se forja a través de una fascinante correspondencia que viaja por el Mar Atlántico iniciada por la catalana con motivo del descubrimiento de la vallisoletana y la fascinación que suscita en ella. El presente trabajo tiene como el análisis de dicho epistolario, poniendo especial atención al nacimiento de una amistad.
\end{abstract}

Palabras clave: amistad, escritoras, posguerra, exilio, correspondencia.

De mar a mar: Correspondence between Ana María Moix and Rosa Chacel

Abstract: De mar a mar is the title of the epistolary that includes the correspondence between the writers Ana María Moix, who is only eighteen and Rosa Chacel, already sixty-seven and exiled in Río de Janeiro. These women begin a sincere friendship that is forged through a fascinating correspondence that travels by the Atlantic Sea, initiated by Moix on the occasion of the discovery of Chacel and the fascination that she arouses in her. More than fifty letters that are read as if it was a story, evidenced the literary quality, the commendable verbal economy of both and increase the interest by the writers of the Spanish pre and postwar period. The present work has the purpose of analizing these letters, paying special attention to the birth of a friendship on their part through the epistolary genre.

Key words: friendship, woman writers, postwar, exily, correspondence.

\section{Introducción y contexto}

El valor que se le atribuye al género epistolar, como el literario o el sociológico y testimonial, pero también el valor con respecto a la expresión de un yo femenino y de la subjetividad femenina, es cada vez más notorio. De acuerdo con María Asunción Gómez:

\footnotetext{
${ }^{1}$ Fecha de recepción: 27/12/2018.

Fecha de aceptación: 26/11/2018. 2 Doctoranda en el programa de doctorado de Estudios Filológicos, Universidad de Sevilla; $\square$ andrea.almudena.s@gmail.com.
} 
Aunque la amistad es objeto de estudio en múltiples ensayos y tema central en obras literarias desde la Grecia clásica hasta la actualidad, la perspectiva ha sido invariablemente androcéntrica. A partir de los años setenta, sin embargo, con el auge de la literatura escrita por mujeres se produce en España también una nueva reconceptualización de la amistad, la sexualidad y las relaciones eróticas femeninas. (Gómez 2008: 246)

Ahora sabemos que la importancia que tienen las cartas es incalculable, pero no siempre se ha considerado de esta forma. En muchas ocasiones las mujeres escribían como forma de agradecimiento, como muestra de admiración, para comenzar o perpetuar una relación sentimental o simplemente para poderse comunicar con alguien ausente. Esto, por supuesto, no suponía amenaza ni problema alguno. Sin embargo, para las mujeres sí implicaba un ejercicio positivo y beneficioso.

Recientemente ha visto la luz De corazón y alma (2017), el epistolario entre Carmen Laforet y Elena Fortún. En el prólogo del mismo, la hija de Laforet da cuenta de la estimación de las misivas como un tesoro único para su madre y de la significación que ambas le atribuían:

Deduje que eran muy valoradas por mi madre, porque yo sabía que el exiguo equipaje que quiso conservar para iniciar una nueva etapa en su vida estaba principalmente compuesto de piezas de valor sentimental e íntimo que fueron poco después, en su mayoría, repartidas entre sus hijos y amigos más queridos, en un afán de aligerar aún más su andadura vagabunda. (Laforet y Fortún 2017: 9)

Las relaciones entre mujeres intelectuales en el siglo $\mathrm{XX}$, concretamente en la inmediata posguerra, suceso que produce un gran vacío existencial y una soledad profunda en muchas de ellas, es un tema que ha recibido una considerable crítica en los últimos veinte años. Las identidades relacional y social eran fundamentales para las mujeres intelectuales, "Esta identidad colectiva se basaba por tanto en los dos factores 
básicos que significaban su nexo de unión: la [escritura] y la condición femenina" (Fernández Urtasun 2013: 219).

Gracias al esfuerzo, en su mayoría de muchas mujeres críticas, hoy podemos revisar la gran cantidad de epistolarios que recogen el sentimiento de unión que, en efecto, se profesaron, las escritoras del pasado siglo. Tenemos a nuestro alcance numerosas muestras que reúnen la correspondencia entre estas mujeres, como también disponemos de una notable cantidad de estudios críticos y de novelas que tratan el eje fundamental en el cual giran: la amistad, “(...) prueba de ello son las numerosas obras de escritoras en las que la amistad femenina adquiere protagonismo argumental" (Cornejo-Parriego 2002: 14).

Carmen Servén (1998) se ocupa de las novelas en las que la amistad se sitúa en el epicentro argumental. En los textos que analiza encuentra puntos en común, siempre referidos a la amistad casi como medio de curación. De acuerdo con ella, Carmen Martín Gaite y Marina Mayoral "coinciden [en sus novelas] en la exaltación de la amistad entre mujeres y del poder benefactor de los códigos privados (...)" (243). Como animales sociales que somos, sentimos la constante necesidad de relacionarnos con otras personas. Tanto las escritoras que nos atañen como en su producción literaria, realizan una celebración de la amistad entre mujeres y una redefinición femenina de la idea de sororidad. Estas amistades van a suponer una nueva forma de entender las relaciones. La mujer se convierte, así, en el individuo que teje su propia red, que toma la decisión de formar un vínculo con otra mujer.

Importante es también la afirmación de Stecher y Cisterna, pues, aunque hablando de las mujeres en Latinoamérica, esta se puede aplicar del mismo modo a nuestro contexto: 
En conjunto con la exploración en la propia subjetividad, los escritos de mujeres latinoamericanas decimonónicas y de las primeras décadas del siglo XX dan cuenta también de una creciente conciencia de la importancia de pensar las relaciones entre mujeres en términos distintos a los de la rivalidad y la competencia. (Stecher \& Cisterna 2016: 101)

La sociedad tiende a desconfiar de las relaciones de amistad entre mujeres y a declararlas incompatibles con la norma social al considerar que, o bien tienen un carácter erótico, o que deben excluirse de cualquier actividad pública por miedo a que esas conexiones, aparentemente inofensivas, consigan convertirse en vínculos de poder que desestabilicen la hegemonía imperante. Comienzan, entonces, las escritoras del siglo $\mathrm{XX}$, a sentirse apoyadas, escuchadas y respaldadas entre ellas, sin tener la necesidad de compararse, restarse autoridad o debilitarse las unas a las otras.

Hay, además, un dato muy importante que apuntó el tratadista retórico Demetrio y que se encarga Ana Baquero de recoger en su obra, La voz femenina en la narrativa epistolar, y es que "se puede decir que cada uno escribe la carta como retrato de su propia alma" (Baquero 2003: 24). Este es, sin duda, un dato muy interesante; si un escrito supone la parte vital de uno mismo, las cartas serían la manifestación más sincera que el ser humano puede crear, idea a la que también se adscribe Biruté Ciplijauskaité “(...) el proceso de compartir la experiencia con el otro, para llegar a una mejor comprensión de uno mismo" (Ciplijauskaité 1992: 398). ${ }^{3}$

Rosa Chacel, nacida en Valladolid el 3 de junio de 1898 y fallecida en Madrid el 27 de julio de 1994, fue muchas más cosas además de una escritora de la Generación del 27. Fue punto de unión entre mujeres, referente para muchas de ellas y apoyo

\footnotetext{
${ }^{3}$ Traducción del original: «( $\left.\ldots\right)$ the process of sharing experience with the other, to come to a better understanding of self» (Ciplijauskaité, 1992: 398).
} 
incondicional para otras. Su exilio en Brasil con paréntesis en Buenos Aires no le impidió seguir cultivando su agudeza intelectual, que se nutrió, en parte, de la correspondencia que mantuvo con numerosas escritoras y numerosos escritores, además de otros artistas. Las cartas de Chacel no solo demuestran su asombrosa valía literaria sino también su importante papel de vínculo entre diferentes generaciones de escritoras españolas.

"Visión y palabra, y memoria y voluntad. Rosa Chacel afirma no haber nunca podido entender nada que no le fuese visible, pues ver era el motor interno de toda su acción" (Trapanese 2015: 103). Vio mucho, en efecto, y vio no solo lo visible, sino también el interior de las personas. Dominaba su faceta emocional a la perfección, era capaz de comunicarse con aquellas personas que le resultan simpáticas o cercanas, pero también con personas que no le sugerían sentimientos positivos.

Ana María Moix Meseguer nace en Barcelona el 12 de abril de 1947 y fallece en la misma ciudad el 28 de febrero de 2014. Esta escritora, fue la única mujer incluida en 1968 por Josep María Castellet en la antología poética Nueve novísimos poetas españoles. Estudiante de Filosofía y Letras y de familia burguesa y conservadora, esta catalana publicó mucho en un espacio temporal muy breve. Se dio a conocer con Baladas del dulce Jim, su primer libro de poesía en 1969 y ratificó su talento con Julia, la novela que nos ocupa, en 1970. Después de pasar una larga temporada sin volver a escribir, retornó con el libro de cuentos merecedor del premio Ciudad de Barcelona, Las virtudes peligrosas, que vio la luz en 1985. A pesar de tener una obra en prosa más extensa que en verso, sus poemarios adquieren de la misma forma una gran importancia en las letras hispánicas: 
En realidad, dentro de esa rebelión juvenil y generacional que impuso una escritura más cosmopolita, culturalista y rabiosamente individualista (...) el nombre de Ana María Moix se presentaba como el de la gran esperanza blanca de las letras españolas del momento (...) con el lanzamiento en cuatro años (de 1969 a 1972) y apenas llegada a la mayoría de edad, de tres libros de poesía -Baladas del dulce Jim, Call me stone y No time for flowers, reunidos después en A imagen y semejanza-, dos novelas importantes, Julia y Walter ¿por qué te fuiste?, y de un libro de relatos, Ese chico pelirrojo a quien veo cada día, todo lo cual causó cierta sensación en el mundo de la literatura juvenil de los años setenta, en la que abría horizontes insospechados. (Conte 2002)

En el caso de Ana María Moix, son famosas las cartas que mandaba a Esther Tusquets (incluso a Milena, la hija de esta, cuando nació) o la correspondencia que mantenía con Cristina Peri Rossi.

Parecido al ya mencionado caso de Elena Fortún y Carmen Laforet, que se escribían cartas para conocerse mejor, “(...) estableció en su interior una amistad inquebrantable con la autora (...)" (Laforet y Fortún 2017: 9), Ana María Moix consigue constituir una comunicación con una autora que en un principio no conoce, Rosa Chacel, y que esta se convierta en una amistad real. El motivo que lleva a la catalana a comenzar el escrito es la necesidad de comunicarle a la filósofa su admiración, la obligación de que sepa que todavía hay jóvenes españoles que la descubren o la redescubren y que sienten que, aún desde el exilio, sigue teniendo cosas importantes que aportar a la literatura española:

Hay que pensar en la posibilidad de enviar estas cartas a su destino para poder escribirlas, y quien sabe sí, desahogada la necesidad de expresarse y hecha la catarsis, ya no es necesario enviarlas. Hace falta una esperanza inicial, aunque débil, o la incertidumbre de que encontrará un lector. Una vez redactada, se ha colmado la necesidad de gestarla y ya se puede destruir sin demasiados reparos, lo cual demuestra que no tenía otro destinatario que nosotros mismos. (Encinar 2000: 48) 
Se trata de una literatura, la que crean las correspondientes, que no pretende ser tal pero que va más allá de cualquier norma preestablecida, como indica Laura Freixas, "La influencia de esas escritoras a su pesar (...) va más allá de lo epistolar” (Freixas 2000: 159). De la admiración a la amistad hay tan solo un pequeño paso. Conocerse sin verse, sin escucharse, solo a través de sus literaturas es lo que hace que estas obras tengan verdadero interés.

Por supuesto, y desde un punto de vista feminista, las cartas son un punto de referencia. Con ellas se produce sororidad, tan importante para las mujeres que necesitaban crear redes con otras mujeres, hablar de con alguien que compartiera su realidad:

Siguiendo los hilos entretejidos por ellas, a través de hemerotecas, biografías, cartas y archivos, se llega a otros nombres de mujer, unos más conocidos, otros menos, unas con obra abundante, otras sin ella, casadas, solteras, con intentas y en ocasiones sáficas relaciones entre ellas, misteriosas casi siempre, obligadas a no resaltar demasiado y a ser discretas en tiempos oscuros; al cabo: feministas. (Laforet y Fortún 2017: 24-25)

Es importante, por tanto, seguir ejercitando la memoria histórica y dar a conocer acontecimientos y situaciones que el paso del tiempo, y otras circunstancias más subjetivas, han tendido a desvanecer. Es vital que entienda el lector o la lectora, o la sociedad en general que estas cartas también son memoria. 


\section{Chacel y Moix: el nacimiento de una amistad}

Ana Rodríguez-Fischer, autora de la recopilación de las cartas que nos ocupa, prologa de forma muy afortunada la comunicación entre estas dos autoras, iniciada, como se ha señalado ya, por la catalana Ana María Moix. "La distancia y ausencia del otro, o el aislamiento y la incomunicación de uno mismo, suele ser la situación humana que origina y desencadena una comunicación epistolar mediante la cual se intentan vencer las lejanías y el silencio" (Chacel y Moix 1998: 9).

Estar lejos de la vallisoletana es, posiblemente, la razón que impulsó a Moix a escribirle después de su lectura de Teresa, publicada en 1941 en Buenos Aires. Ana María, impresionada por la caracterización del personaje principal de la obra como una especie de 'chica rara', consigue averiguar la dirección de Chacel, que en ese momento se encuentra en Río de Janeiro, y tímidamente le escribe: "Me he llevado una gran sorpresa al leerla puesto que, a pesar de estar al corriente de lo que se publica, nunca hasta ahora había caído en mis manos un libro suyo. (Debo hacerle la advertencia que tengo 18 años)" (Chacel y Moix 1998: 21). Quizá si ambas hubieran vivido en la misma ciudad o, en el menos venturoso de los casos, en el mismo país, nos hubiéramos perdido esta maravillosa historia, porque lo que no queda escrito no existe.

Esta comunicación supuso un gran esfuerzo, no solo por el tiempo que requería escribir unas larguísimas cartas, unas veces telegrafiadas, y otras escritas a mano, sino por el coste monetario que conllevaban. Recordemos que partían de Barcelona hasta Río de Janeiro y viceversa:

Fue mucha la habilidad -económica o no- desplegada por Rosa Chacel para poder alimentar durante largos años un coloquio epistolar tan amplio y plural como fue el 
suyo. Porque no solo se carteó con los amigos y compañeros de su generación o de su grupo, sino que desde la distancia, y en ocasiones sin que mediara un contacto personal, supo o pudo entablar un diálogo intenso y transparente (...). (Chacel y Moix 1998: 11)

Moix le expresa con un tremendo respeto a Chacel, incluyendo un "Sra. Rosa Chacel" en el saludo de sus escritos y "Cordialmente" en la despedida, mientras que la filósofa le dedica palabras más tiernas y cálidas, a lo mejor por la diferencia de edad, como "Querida Ana María" o "Con mi sentido afecto". La catalana le demuestra su admiración siendo estrictamente correcta, quizá con temor a ser rechaza.

Se complace de haber encontrado una novelista que de verdad mereciera la pena inmersa en el aire contaminado y cargante de la novela española de posguerra, de la dictadura franquista o la Transición a la democracia. Cierto es que resultaba tan gratificante como una bocanada de aire fresco encontrarse con trabajos tan brillantes como los que presentaba Rosa: "Su prólogo de Teresa me ha parecido muy inteligente (acepte mi modesto halago) y muy interesante para mí en estos momentos en que la novelística española no sabe por dónde va. Las universidades no nos ayudan en nada; leemos de aquí y de allí, y en cuanto surge la intuición sale la obra" (Chacel y Moix 1998: 22).

La respuesta de Chacel no podía ser más positiva y encuentra en su correspondiente la representación de lo que debería ser su país, un país que le obligó a exiliarse. Seguramente desde el comienzo vea en Moix un reflejo de su propia persona: “(...) su arrojo para escribirme, sin pereza ni inhibición de ningún género, me traen el testimonio de que España existe y continúa. (...) Le repito que su carta ha sido para mí un acontecimiento feliz y que contestaré con verdadero placer a todas sus preguntas, que espero sean inagotables" (Chacel y Moix 1998: 24-28). 
Ya desde muy joven nace en la catalana la pasión por la escritura:

Escribo desde hace bastante tiempo dos libros de poesías, uno en catalán: Temps de l'home (Tiempo del hombre), y otro en español, Una piedra en el camino. (...) Además unos veinte cuentos. (...) También he escrito una novela corta, Mil soles en silencio. (...) Tengo en proyecto tres novelas y algo de crítica literaria: son ideas, de repente decae mi estado interior y soy incapaz de escribir dos líneas. Afortunadamente me repongo, unas veces dura más, otras menos. (Chacel y Moix 1998: 30)

Además, muestra un gran interés en ser una buena escritora y le pide consejo a Chacel, en la que encuentra un buen referente: “¿Cómo debe ser hoy la novela? ¿Qué es lo superado? ¿Cómo se consigue la fidelidad a uno mismo, dejando de lado lo gratuito, lo falso y lo fácil?” (Chacel y Moix 1998: 31). Según Rosa Fernández Urtasún, “La fuerza de la carta y la claridad de sus ideas son muy importantes. En un contexto de sospecha constante hacia lo que querían hacer, el consejo y el ánimo de una amiga empeñada en la misma tarea resultaba decisivo" (Fernández Urtasun 2013: 221).

Los elogios son constantes y sinceros; la vallisoletana le anima a escribir, para lo que advierte que tiene ya un gran talento: “(...) quiero decir que en este demuestra usted un dominio de la lengua, una soltura y una precisión que excluyen toda duda sobre su destino literario. Sí, es evidente, no tiene usted más remedio que escribir" (Chacel y Moix 1998: 34). También le alaba que haya dado el paso de ponerse en contacto con ella:

No me extraña que los jóvenes se abstengan a veces de abordar a los escritores de otra generación porque sé por experiencia que pueden resultar estúpidamente olímpicos o fríamente bien educados -cuando no francamente mal educados-, pero usted ha podido comprobar que yo no soy temible porque mi mayor ambición es que sean ustedes, precisamente ustedes, los de su tiempo, mis lectores. (Chacel y Moix 1998: 38) 
Moix le habla de la universidad y de las revueltas de los estudiantes. Ella, como Julia el personaje que creará años más tarde en la novela de mismo nombre, no es una adolescente como otra cualquiera. Es una muchacha con un historial personal y psicológico bastante delicado. Ya desde pequeña muestra signos de ser una niña inquieta, a veces incluso demasiado emocional. Es introvertida y en ningún momento aclara sus sentimientos:

De nuevo he comenzado las clases, un poco agitadas por los conflictos universitarios existentes por aquí. Hoy hemos tenido elecciones clandestinas y no sé cómo acabará todo esto. Entretanto estudio algo, leo, veo cine y teatro e intento escribir. (...) Este mes he empezado mi primer año de universidad. ¿Era la gente de época estudiantil tan anodina como la de ahora? ¿Cómo es la gente joven en Río de Janeiro? (Chacel y Moix 1998: 42-47)

Chacel, que como se ha advertido ya antes, dedicaba mucho tiempo a escribir cartas y consideraba este un ejercicio importantísimo. Entendía que no era una simple comunicación la que mantenía con aquella joven entusiasta, sino que, al tratarla como una igual, debía realizar un esfuerzo intelectual considerable: "Como no sé escribir una carta breve y, además, no tendría sentido escribirla pues solo se trata de hablar, de comunicarnos, ya que afortunadamente se ha producido por sí misma esta inesperada comunicación, tengo que encontrar un rato largo de tranquilidad para ponerme a la máquina y esto no ocurre todos los días” (Chacel y Moix 1998: 48-48).

La vallisoletana se interesa por la vida de su interlocutora y le pide detalles acerca de su personalidad: "Un día que cuente con tiempo para hacer un poco de historia deme algunas noticias de su vida pues en el aludido triángulo -o pentágono, o dodecágonoestán las raíces de nuestra mente y hay que conocer la tierra de que se nutre" (Chacel y Moix 1998: 52-53). 
La descripción que de sí misma hace Ana María no carece de importancia, todo lo contrario, es, de nuevo, el paralelismo con Julia lo que nos llama la atención. Dice que fue una niña rara, más lista que los demás. Aparte de esto, debido a su hermetismo, nadie es capaz de saber cómo es realmente; la falta de empatía de sus familiares incrementa el sentimiento de incomprensión en la niña, que entra en un círculo vicioso de marginación:

Mi historia es breve. Nací en Barcelona. Mi familia pertenece al repelente rango de la pequeña burguesía catalana que a principios de siglo puso las bases de una leyenda sobre un montón de fábricas y se durmió en ella. Como la vida social, la de por encima, no me importa si es para desarrollar mis tendencias a la ironía, desde pequeña he hurgado en la vida interior de este medio. (...) Yo [lo] que detesto [es] la hipocresía. (...) Dicen que he sido una niña precoz, rara y casi "monstruo". A los ocho años en el colegio llamaron a mis padres: en enseñanza media no sabían qué enseñarme y para bachiller me faltaban dos o tres años. Fui acogida en el seno orgulloso de la familia; era maleducada y extraña, pero por lo menos estudiosa (esto le mostrará lo mal que se sigue educando en España). (Chacel y Moix 1998: 59-60)

Puede que desarrollara mecanismos de defensa debido a la ansiedad y angustia que vivió. Ana María Moix toma la decisión de escoger el tipo de personaje de Julia frente a otro precisamente para evidenciar esa terrible distancia entre un joven y sus padres en el momento de la vida en que menos cosas tienen en común:

Quedan muchas cosas que decir: Muchas. Épocas terribles de desánimo. Desengaños con la gente, cuyo trato me es difícil, aún no sé por qué. Descubrimientos prematuros en la vida privada de la familia: engaño, fingimiento, hipocresía. Planteamiento de suicidio (incluso intentos). Luego, un inexplicable amor por todo. (Chacel y Moix 1998: 61)

De nuevo un símil; el físico. Recordemos que Julia tiene mal aspecto, está excesivamente delgada, pálida y sin ganas de arreglarse: "De mi época de aburrimiento -yo sola, apática, insoportable-prefiero no hablar. Físicamente soy normal: delgada, y, 
para disgusto de mi madre, demasiado" (Chacel y Moix 1998: 61). Tal y como afirma Antonia Ferriol-Montano, “(...) la recuperación de la amistad de la adolescencia como escapatoria frente a la soledad humana" (Ferriol-Montano 2002: 100) se convierte en algo fundamental para las mujeres.

A esto le responde Chacel que ella también es peculiar. "Que me aguantes tú te demuestra lo fuerte que eres" (Chacel y Moix 1998: 131), "Y la verdad es que yo choco nada más aparecer, sin abrir la boca: puedo decir que soy una verdadera mujer fatal para las antipatías. Pero no se asuste demasiado; estoy dispuesta a reaccionar, sea como sea (Chacel y Moix 1998: 70).

Es tal el entusiasmo de Moix y la fascinación sincera que le promete empeñarse en que no se convierta en una olvidada y ausente, en que todo el mundo conozca y lea a Rosa Chacel: "Le aseguro que los jóvenes españoles de hoy van a conocer su obra (en la medida que yo lo pueda conseguir $-\mathrm{y}$ al afirmarlo casi me siento ridícula). Las obras que tengo de usted se leerán. (Será ocasión de comprobar si hemos avanzado o no)" (Chacel y Moix 1998: 75).

Hay un momento en toda comunicación por carta en el que las interlocutoras lamentan la distancia que las separa y piensan que la realidad sería diferente de no haber esta traba: "De vivir usted aquí hubiésemos hablado mucho -de hecho, así ha sido; incluso no era yo sola quien hablaba, sino que oía sus respuestas y explicaciones. No sabe cuánto he deseado que estuviera aquí. En aquellos momentos me era muy difícil escribir” (Chacel y Moix 1998: 100), y surge la desesperación por obtener noticias del otro: "Por favor, escríbame pronto, pronto, pronto, y si le es posible más, más pronto" (Chacel y Moix 1998: 103). "Espero su carta con la ansiedad de siempre (con más 
ansiedad que nunca porque la necesito mucho más)" (Chacel y Moix 1998: 127). "Te abrazo violentamente" (Chacel y Moix 1998: 163).

Chacel haciendo uso de su condición de filosofa, se preocupa por el estado de salud de Ana María y le da consejos para que se libere de su peor enemiga, que no es más que ella misma: "Pero... para decirlo con todas sus letras, lo que te falta, lo que te es vitalmente necesario es liberarte de ti misma. Lo que te hace falta es ejercer tu libertad, la que tienes, inalienable, si sabes echar mano de ella, si dominas a tu demonio, que es el que te esclaviza (...)" (Chacel y Moix 1998: 107).

En esta correspondencia también hay lugar para el amor. La joven Moix tiene une idea bastante definida de lo que considera de este sentimiento: "He decidido que si algún día me da por enamorarme seré yo quien lo haga. Detesto el que "me enamoren", los gloriosos amantes que aparecen en la esquina con un poema en la mano, y que creen que así aman” (Chacel y Moix 1998: 115). La amistad evoluciona tan rápido que las confesiones adquieren un carácter muy personal e íntimo. Según María Asunción Gómez: "Mediante una lectura atenta de De mar a mar (1998) -título de la publicación que recopila las cartas que ambas autoras se escribieron a lo largo de su vida- Cornejo Parriego observa cómo del mero intercambio intelectual, las autoras se van deslizando paulatinamente hacia temas más íntimos y personales" (Gómez 2008: 247).

La joven Ana María confiesa haber acudido al psiquiatra, pues la actitud de muchacha roza en ciertos puntos la esquizofrenia. El desorden cerebral de Moix se reflejó en sus acciones contradictorias.: "Decidí ir a visitar a un psiquiatra, al que ya visité hace cosa de un año, y hora voy a hacer todos los posibles para aguantar el tratamiento el tiempo que sea necesario" (Chacel y Moix 1998: 128-129). 
Chacel le ofrece la posibilidad de que le visite en un futuro y se quede en su casa: "Si este quimérico proyecto se llevara a cabo dentro de este año, podría ofrecerte un rinconcito minúsculo para las vacaciones de Navidad (...)” (Chacel y Moix 1998: 136). Moix cambia la forma de tratamiento, pasa del usted al tú, previa petición la de filósofa: "Hoy mismo he recibido tu carta (perdone si de repente de me sale el usted), y te contesto ahora para no dar lugar a ese horrible pensamiento de que te olvido" (Chacel y Moix 1998: 149).

Rosa Chacel valora la amistad de Ana María Moix con Pere Gimferrer y Guillermo Carnero; en ellos ve un futuro, la salvación de España:

\begin{abstract}
Vuestra unión, armonía, concordancia o como quieras llamarle, me conmueve. Pero no solo me conmueve; me da una gran esperanza. Todo lo que en España se ha hecho -sencillamente, todo- ha sucumbido por falta de cohesión. Tú te enorgulleces de ellos, ellos se enorgullecen de ti... (Chacel y Moix 1998: 171).

El triunfo de Pedro [Premio Nacional de Literatura en 1966] me alegra no solo por él (...) sino porque se demuestra que no se ha perdido enteramente en España el sentido de la excelencia. Figúrate cómo me alegra saber que va a salir tan pronto el libro de Guillermito; así, paso a paso, iréis imponiéndoos, creando otro ambiente, modificando la luz hasta que eso vuelva a ser un mundo habitable (Chacel y Moix 1998: 223).
\end{abstract}

Hablan de otras escritoras, fortalecen vínculos, crean nexos: "El libro de Ana María Matute que leíste en Madrid es Primera Memoria (...). Te mandaré algún libro de Carmen Kurtz (...)" (Chacel y Moix 1998: 190). Afloran sentimientos fuertes que disfrazan el miedo a la pérdida: “Tienes la obligación de recuperarte para que yo pueda ver que todo era verdad, y yo me tomo el derecho de recordártelo y asegurarte que lo era. ¿Vale la pena?” (Chacel y Moix 1998: 202), "No has vuelto a decirme si duermes bien o tomas somníferos. QUIERO QUE ME CONTESTES A ESTO CATEGÓRICAMENTE” (Chacel y Moix 1998: 213). 
Ana María siente celos por la extensión de las cartas a sus amigos, con las que compara las que Chacel le manda a ella y le reprocha en su carta con un enfado dramático que casi roza la comicidad: "Tres páginas tiene la carta que he recibido hoy, y tres la anterior, las de Guillermito, punto y coma, ¡son de cinco! No sabía que fuera celosa, pero ahora ya lo sé. Me siento abandonada en el arroyo, ¡caída en desgracia!, ¡desechada!, ¡casi olvidada! (...)" (Chacel y Moix 1998: 231). También se vuelve recelosa con sus pertenencias y no permite que nadie lea esas intimidades que se convierten un secreto tan solo entre ellas dos: “A propósito de mis pertenencias: tus cartas no se las dejo a los otros dos (qué despectivo me ha salido, pobres" (Chacel y Moix 1998: 234).

La comunicación entre Rosa Chacel y Ana María Moix sufre paros temporales debido a la frustración de la vallisoletana con la escritura de su obra Desde el amanecer: (...) no hay la menor perspectiva de que salga mi libro [Desde el amanecer]. Todo esto produce algo muy parecido a una enfermedad grave" (Chacel y Moix 1998: 258). Esta ausencia del otro, que se deja llevar por el tiempo, también produce en Moix un sentimiento de soledad: "No sabes cuánto he pensado en ti; he lamentado que estés tan lejos cada día. Nunca me sentí tan sola; lo sabía, pero no tan realmente y a sabiendas de que es así, no solo para mí, sino para todo el mundo y que nadie puede ayudar a nadie (...)" (Chacel y Moix 1998: 304).

En las últimas cartas entre estas dos escritoras se palpa un cambio sustancial, pero a pesar de eso parece haber cierta resignación, como si el camino que la amistad debiera tomar fuera exactamente ese. Le suplica Chacel a Moix "Contéstame en seguida y sigue siendo fuerte y magnífica, tal como yo sé que eres" (Chacel y Moix 1998: 308), a lo que la catalana le contesta: "Tus cartas siguen siendo un motivo de alegría muy grande para mí, ya lo sabes. Siempre que te escribo espero la respuesta como la primera vez que te 
escribí” (Chacel y Moix 1998: 316). Le pide Rosa Chacel a Ana María Moix: "Cuídate mucho, sálvate, sácate del pozo" (Chacel y Moix 1998: 340). Le contesta la catalana en 1970: “(...) yo diría que amé tus cartas, y a ti, a través de ellas; mejor dicho, lo que yo inventé de ti a través de unas cartas" (Chacel y Moix 1998: 360).

Moix, en su última carta fechada en 1975, de la que ya nunca obtendrá una respuesta, firma ya solo como "Ana” (Chacel y Moix 1998: 370), detalle que añade privacidad y una nota íntima a su despedida, como dos viejas amigas que se despiden ya para siempre.

\section{Conclusiones}

Podemos concluir que la relación entre las dos escritoras pasa por cuatro etapas fundamentales. La primera correspondería al 'descubrimiento del otro', "Me he llevado una gran sorpresa al leerla (...)" (Chacel y Moix 1998: 21). La segunda sería "Nacimiento de la amistad. Necesidad de información del otro" "Un día que cuente con tiempo para hacer un poco de historia deme algunas deme algunas noticias de su vida (...)" (Chacel y Moix 1998: 52-53). La tercera, 'Sentimientos afectivos incipientes', "Que me aguantes tú te demuestra lo fuerte que eres" (Chacel y Moix 1988: 131). Por último, la cuarta, 'Punto álgido. Sentimientos de dependencia emocional' "Espero su carta con la ansiedad de siempre (con más ansiedad que nunca porque la necesito mucho más” (Chacel y Moix 1988: 127).

Ana María Moix, a sus 18 años buscaba una mentora que le iluminara el camino y le ratificara lo que ya sentía: esa necesidad imperiosa de ser escritora. En las cartas, Moix se lanzó a sincerarse con fuerza y autenticidad y la veterana autora de la 
República recogió el guante como a quien le va la vida en ello. No pueden ser más distintas en carácter, pero se entienden a la perfección. Moix es apasionada. Chacel lo fue en su juventud, pero ahora, gran pesimista, se ve obligada a refugiarse de vez en cuando en sus silencios que de vez en cuando la dejan fuera de juego y le impiden contestar a su ferviente corresponsal. Al final, lo único que queda es una imponente necesidad de comunicación y, sobre todo, de alimentar una sincera amistad.

\section{Referencias bibliográficas}

Baquero, Ana. 2003. La voz femenina en la narrativa epistolar. Cádiz: Universidad de Cádiz.

Ciplijauskaite, Biruté. 1992. "Lyric memory, oral history, and the shaping of self in spanish narrative”. Forum for Modern Language Studies, 28: 390-400.

Chacel, Rosa y Ana María Moix, 1998. De mar a mar. Barcelona: Península.

Conte, Rafael. 2002. "La elegancia del equilibrio". El País / Babelia. 5 de octubre.

Cornejo-Parriego, Rosalía. 2002. "Entre érôs y philía: amistades femeninas en la obra de Marina Mayoral”. Journal of Iberian and Latin American Studies, 1: 13-28.

Encinar, Ángeles. 2000. "La narrativa epistolar en las escritoras españolas actuales". Mujeres novelistas en el panorama literario del siglo XX. Coord. Marina Villalba Álvarez. Cuenca: Universidad de Castilla-La Mancha. 33-50.

Fernández Urtasun, Rosa. 2013. "Amistad e identidad: Las poetas españolas de los años 20”. Epos. Revista De Filología, 29: 213-226.

Ferriol-Montano, Antonia. 2002. "Identificación, intercambio y libertad en la amistad femenina: La creación del "nosotras" en Nubosidad variable de Carmen Martín Gaite". Letras Femeninas, 28: 95-114.

Freixas, Laura. 2000. Literatura y mujeres. Barcelona: Destino.

Gómez, María Asunción. 2008. "Entre mujeres. política de la amistad y el deseo en la narrativa española contemporánea". Letras Femeninas, 34: 246-249.

Laforet, Carmen y Elena Fortún. 2017. De corazón y alma (1947-1952). Madrid: Cuadernos de Obra Fundamental, Fundación Banco Santander. 
Moix, Ana María. 1970. Julia. Barcelona: Lumen, 1991.

Servén, Carmen. 1998. "La amistad entre mujeres en la narrativa femenina: Carmen Martín Gaite (1992) y Marina Mayoral (1994)". Dicenda, 16: 233-243.

Stecher, Lucía y Natalia Cisterna. 2016. "Escenas de amistad femenina en luz y sombra de Ana Roqué y las Memorias de mamá blanca de Teresa de la Parra: Pensar y definir el yo en la intimidad". Anales De Literatura Hispanoamericana, 45: 99120.

Trapanese, Elena. 2015. "Rosa Chacel: entre circunstancias y voluntad". Philobiblion: Revista de literaturas hispánicas, 1: 95-109. 